\title{
Endothelial nitric oxide synthase, vascular integrity and human exceptional longevity
}

\author{
Annibale Alessandro Puca ${ }^{1,2}$, Albino Carrizzo ${ }^{3}$, Anna Ferrario ${ }^{1}$, Francesco Villa ${ }^{4}$ and Carmine Vecchione ${ }^{2,3^{*}}$
}

\begin{abstract}
Aging is the sum of the deleterious changes that occur as time goes by. It is the main risk factor for the development of cardiovascular disease, and aging of the vasculature is the event that most often impacts on the health of elderly people. The "free-radical theory of aging" was proposed to explain aging as a consequence of the accumulation of reactive oxygen species (ROS). However, recent findings contradict this theory, and it now seems that mechanisms mediating longevity act through induction of oxidative stress. In fact, calorie restriction - a powerful way of delaying aging - increases ROS accumulation due to stimulation of the basal metabolic rate; moreover, reports show that antioxidant therapy is detrimental to healthy aging. We also now know that genetic manipulation of the insulin-like-growth-factor-1/insulin signal (IIS) has a profound impact on the rate of aging and that the IIS is modulated by calorie restriction and physical exercise. The IIS regulates activation of nitric oxide synthase (eNOS), the activity of which is essential to improving lifespan through calorie restriction, as demonstrated by experiments on eNOS knockout mice. Indeed, eNOS has a key role in maintaining vascular integrity during aging by activating vasorelaxation and allowing migration and angiogenesis. In this review, we will overview current literature on these topics and we will try to convince the reader of the importance of vascular integrity and nitric oxide production in determining healthy aging.
\end{abstract}

Keywords: eNOS, Longevity, Aging, Vascular integrity

\section{Introduction}

Max Rubner's "rate of living" theory [1] combined massspecific resting metabolic rate and maximum lifespan of mammalian species to calculate the "lifetime energy potential": it holds that the pace of life is inversely related to the length of life. Raymond Pearl [2] used this concept to explain longevity variation within species and gave it the "rate of living" label.

The subsequent "free-radical theory of aging" (FRTA) was formulated from the above concepts: Harman [3] postulated that accumulation of free radicals was the prime cause of the sequential alterations characterizing advancing age and the progressive increase in disease and death rates [4].

With the introduction of a "lipids" perspective to the FRTA, it was then asserted that the level of peroxidizability of the cell membrane bilayer was a critical determinant

\footnotetext{
* Correspondence: cvecchione@unisa.it

${ }^{2}$ Department of Medicine and Surgery, University of Salerno, Salerno, Italy

${ }^{3}$ Vascular Physiopathology Unit, IRCCS INM Neuromed, Pozzilli, (IS), Italy

Full list of author information is available at the end of the article
}

of the severity of cell damage caused by free radicals: in response to attack by free radicals, peroxidation - the susceptibility to which is dictated by the number of single-bonded carbon atoms between the $-\mathrm{C}=\mathrm{C}$ - units of the fatty acyl chain - generates a strong self-propagating reaction that causes damage to other molecules [5].

The "membrane pacemaker" theory of aging incorporates these concepts to hold that high membrane fluidity and low membrane peroxidizability are the optimal membrane conditions for promoting longevity. This theory arose from the observation that body mass/maximum lifespan in mammals and birds correlates respectively directly and inversely with the levels of C18:1n-9 and C22:6n-3 fatty acids in cellular membranes. This can be explained by the fact that C22:6n-3 is 320 -fold more susceptible than C18:1n-9 to peroxidation, while the latter fatty acid has fluidity properties as good as the former [6].

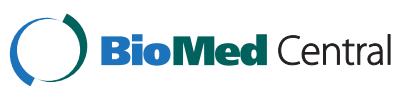

(c) 2012 Puca et al.; licensee BioMed Central Ltd. This is an Open Access article distributed under the terms of the Creative Commons Attribution License (http://creativecommons.org/licenses/by/2.0), which permits unrestricted use, distribution, and reproduction in any medium, provided the original work is properly cited. 


\section{Lipids, eNOS and exceptional longevity}

Exceptional longevity in humans is a complex trait. Long-living individuals have delayed aging and a low incidence of cardiovascular disease $[7,8]$. We recently reported that in children of nonagenarians the peroxidation index of erythrocyte membrane lipids was significantly lower than in a group of matched controls [9]. It is of particular interest that we found significantly increased levels of palmitoleic acid (C16:1n-7) in the nonagenarians' offspring, similarly to what was later observed in genetically modified long-living worms [10]. Because these worms were genetically modified in homologue genes of the insulin-like growth factor 1 (IGF1)/forkhead box O3 (FOXO3A) axis, a possible explanation for this finding is that IGF-1 signalling modulates, or is modulated by, the membrane fatty-acid composition [11]. Moreover, it was reported that after chronic thermal or saline stress of yeast, the induced increase in the level of membrane palmitoleic acid was responsible for a reset of heat shock protein (Hsp) release to higher levels [12]. Thus, the high C16:1n-7 detected in the offspring of nonagenarians could be correlated to the low serum level of Hsp70 detected in centenarians' offspring [13].

In apparent contrast with the FRTA is the finding that the cell membranes of offspring of nonagenarians as well as of long-living DAF2 Caenorhabditis elegans mutants have an accumulated amount of endogenous trans fatty acids [9 and unpublished data]. Endogenous trans fatty acids are an index of endogenous free-radical cellular stress and are produced by endothelial nitric oxide synthase (eNOS)-generated nitrates $\left(\mathrm{NO}_{2} \cdot\right)$, as shown by the lack of trans-arachidonic acids in the retinas of $\mathrm{eNOS}^{-1-}$ mice [14]. Moreover, calorie restriction has been shown to increase longevity in organisms ranging from yeasts to mammals; it induces the expression of eNOS and mitochondrial biogenesis, which in turn increases oxygen consumption. These effects were abolished in $\mathrm{eNOS}^{-/-}$mice [15]. We therefore speculated that eNOS, nitrate radical stress and the trans fatty-acid accumulation observed in nonagenarians' offspring are all interconnected in the delayed-aging action of calorie restriction, in apparent contrast with the FRTA [16]. The trans fatty acids could serve as molecular signals that ultimately induce endogenous defence mechanisms culminating in increased stress resistance and longevity, an adaptive response named hormesis [17].

In agreement with this hypothesis, deletion in worms of mitochondrial proteins such as ISP-1 and NUO-6 induces the oxidative stress necessary and sufficient for promoting longevity: in fact, this effect is abolished by antioxidants and is induced by mild treatment with oxidants [18]. Taken together, these findings question Harman's FRTA and suggest, rather, that reactive oxygen species (ROS) act as essential signalling molecules promoting metabolic health and longevity through an eNOS/nitrate/trans fatty acids axis [19]. The degree of oxidative stress could possibly explain this apparent paradox: low stress being protective, whereas massive stress becomes deleterious.

\section{Calorie restriction, exercise, genetic makeup and eNOS}

The beneficial effects of calorie restriction are multiple: it reduces the incidence of tumours and diabetes and the age-related decline in T-lymphocyte proliferation [20]. The effects of calorie restriction can be explained by increased IGF1-insulin signal (IIS) efficiency: in fact, findings on patients with growth hormone receptor deficiency suggest that their high insulin sensitivity could account for the absence of diabetes and very low incidence of cancer seen in these individuals [21].

Furthermore, calorie restriction can be mimicked by genetic manipulation aimed at blocking IIS (i.e., the IGF1/PI3K/AKT/FOXO3A axis): for example, the FIRKO mouse - a carrier of a fat-specific insulin receptor knockout - and C. elegans models carrying null mutations of daf-2 - an IGF1 homologue - and age-1 - a homologue of the catalytic subunit of mammalian PI3K- all live longer than wild-type animals $[22,23]$. To be noted, the beneficial effects of $d a f-2$ and age- 1 null mutations are antagonized by null mutation of daf-16, which encodes three members of the FOXO family of transcription factors [23]. Thus, via AKT the IIS is important for controlling eNOS and, hence, human longevity [24].

Genetic variants that are either protective or deleterious for human health can be identified by studying the genetic pool of centenarians: the so called "positive biology approach" $[25,26]$. Interestingly, apolipoprotein E (APOE) - a variant of which is associated with exceptional longevity in humans across populations - controls the IIS pathway by influencing PI3K [27]. Similarly, the presence of genetic variants of FOXO3A - another member of the IIS - is highly replicable in long-living populations [28-30].

Exercise is inversely correlated with total mortality [31]. An elegant report on athletes undergoing marathon training identified a combination of metabolites (i.e., glycerol, niacinamide, glucose-6-phosphate, pantothenate and succinate) that increased in the plasma in response to exercise; in vitro, these metabolites were able to up-regulate the expression of NUR77, a transcriptional regulator of glucose utilization and lipid metabolism genes [32]. NUR77 is under the control of $\mathrm{Ca}^{2+} /$ calmodulin-dependent protein kinase (CAMKIV), which is activated by AMPK and has been associated with human exceptional longevity [33,34]. Furthermore, AMPK controls eNOS phosphorylation, which explains the potentiation of eNOS activity by both calorie restriction and physical exercise [24]. AMPK is activated acutely at exercise intensities above $\approx 60 \%$ of maximal 
aerobic capacity [35]. Calorie restriction and exercise both activate mitochondrial biogenesis through activation of AMPK with an eNOS-dependent mechanism, as shown by experiments on eNOS knockout mice [36]. Thus, the beneficial effects on longevity of calorie restriction, genetic makeup and exercise can be explained, at least in part, through eNOS-dependent activation of mitochondrial biogenesis.

\section{Vascular endothelial dysfunction and eNOS in aging}

Endothelial dysfunction is the hallmark of vascular damage in advancing age [37-41]. Many functions of the vascular endothelium are modulated by $\mathrm{NO}$, which is able to induce smooth muscle relaxation [42-44], the inhibition of platelet aggregation [45], leukocyte adhesion to endothelial cells $[46,47]$ and preservation of endothelial progenitor cell function [48] (Figure 1a). The crucial role of $\mathrm{NO}$ in protecting the cardiovascular system during aging was revealed by studies demonstrating that eNOS knockout mice have a premature cardiac-aging phenotype and early mortality [49].

Reduction of NO availability alters vascular homeostasis [50] and is a phenomenon involved in the development of hypertension [50,51], atherosclerosis and thrombosis leading to heart attack and stroke [52-54]. The mechanisms underlying vascular aging are complex and involve multiple pathways $[41,55,56]$ (Figure 1b). During aging, there is a progressive misbalance between
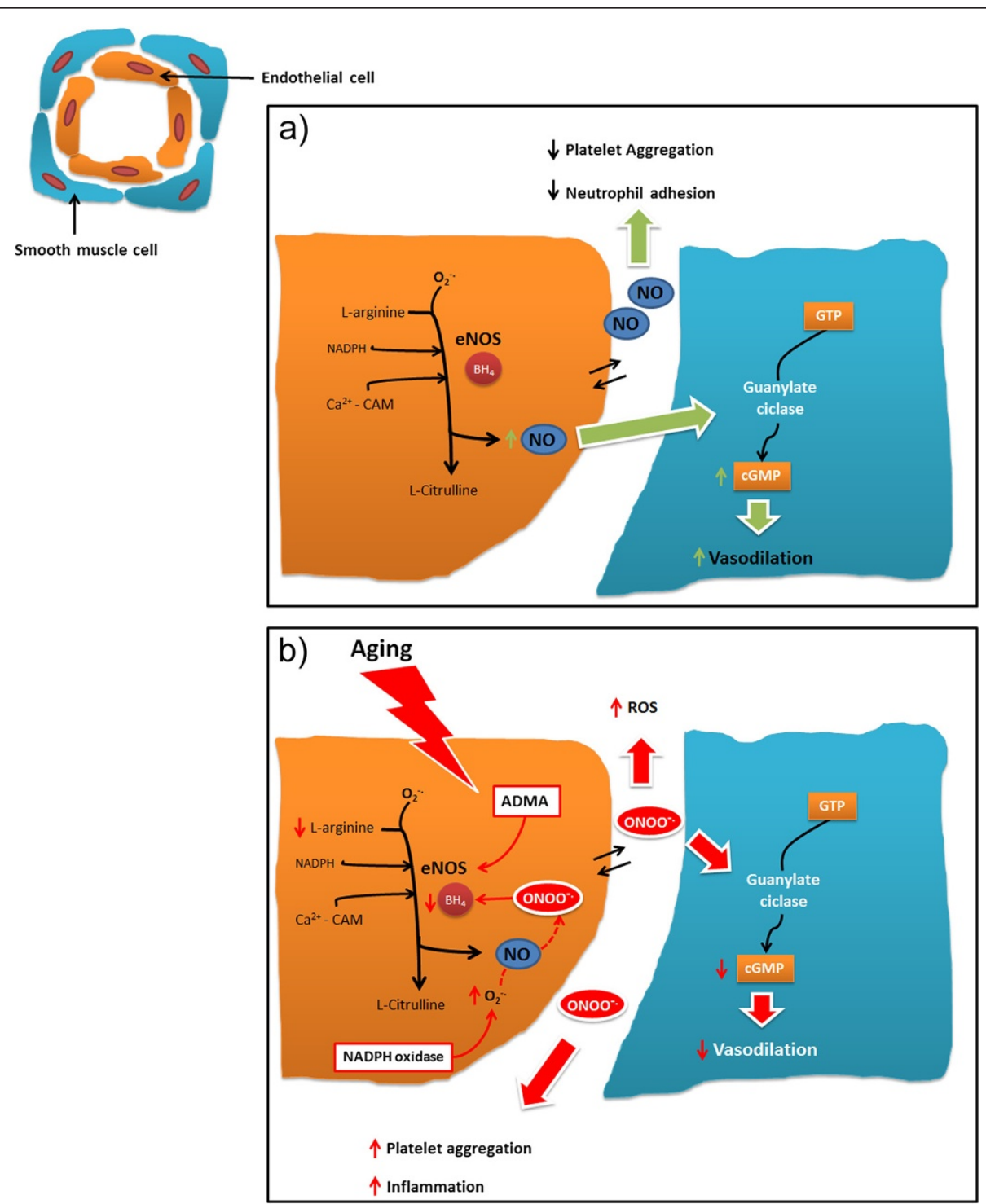

Figure 1 a) Representative nitric oxide pathway. b) Effects of aging on nitric oxide pathway. $\mathrm{BH}_{4}=$ tetrahydrobiopterin; $\mathrm{Ca}^{2+}=\mathrm{calcium}$ ion; CGMP = cyclic guanosine monophosphate; eNOS = endothelial nitric oxide synthase; GTP = guanosine triphosphate; NADPH = nicotinamide adenine dinucleotide phosphate; $\mathrm{NO}=$ nitric oxide; $\mathrm{ONOO}^{-}$= Peroxynitrite; $\mathrm{ADMA}=$ Dimethylarginine; $\mathrm{ROS}$ = reactive oxygen species. 
NO production - which becomes increasingly reduced and oxidative stress - which increases without a compensatory enhancement of antioxidant defences [57-59]. As a result, aged vessels have a compromised vasodilatory function, which induces increased vascular resistance and impaired perfusion [60]. Reduced NO production may be dependent upon several mechanisms, including: a) deficiency in eNOS substrates and cofactors, such as l-arginine [61] and tetrahydrobiopterin (BH4) [62]; b) the presence of endogenous eNOS inhibitors, such as asymmetric dimethylarginine (ADMA) $[63,64]$ and analogues of 1 -arginine present in plasma and various tissues, which have been described as cardiovascular risk factors [65]; and c) lower expression and/or activity of eNOS due to abnormalities in eNOS trafficking to caveolae, to altered eNOS phosphorylation status or to uncoupling of eNOS activity $[39,66,67]$.

An important molecule regulating eNOS activity is sirtuin 1 (Sirt-1), a longevity factor that modulates cellular senescence [68] and promotes endothelium-dependent vasodilation by targeting eNOS for deacetylation [69]. Sirt-1 expression was found lower in endothelial cells from older adults than healthy younger individuals $[66,70]$ in which endothelial vasorelaxation was demonstrated to be positively related to Sirt-1 expression. Calorie restriction - which improves health and slows the aging process - has been reported to induce eNOS expression, improve mitochondrial biogenesis and increase Sirt-1 expression; thus, a positive feedback loop links Sirt-1 and eNOS [71], and activation of SIRT1 may help to reset the activity of eNOS during situations of endothelial dysfunction where NO availability is limited.

BH4 is an essential cofactor for NO synthesis by eNOS. When it is limited - because of a decrease in biosynthesis or an increase in its oxidation - eNOS becomes uncoupled and induces release of superoxide, which, in turn, leads to degradation of NO. Administration of $\mathrm{BH} 4$ to older adults caused a selective improvement in endothelial vasorelaxation, demonstrating that BH4 potentially leads to eNOS recoupling in aged human vasculature [72].

Another mechanism that reduces NO bioavailability, hence contributing to vascular endothelial dysfunction with aging, is oxidative stress [73]. Oxidative stress is induced mainly by uncoupling of eNOS, upregulation of the oxidant enzyme nicotinamide adenine dinucleotide phosphateoxidase (NADPH oxidase) $[50,74,75]$ or increased mitochondrial production of ROS [76-79]. Increased expression of NADPH oxidase has been reported in vessels from aged humans not presenting with other cardiovascular risk factors. The use of NADPH inhibitors protects from agerelated endothelial dysfunction [80].

Finally, a reduction in the number of mitochondria and an increase in the generation of dysfunctional proteins have been linked to aging through increased oxidative stress and mitochondrial DNA damage [81]. The mechanisms of mitochondrial oxidative stress in aged endothelial cells include also inhibition of antioxidant defence enzymes, such as manganese superoxide dismutase (MnSOD) [82], decline in reduced glutathione content [83] and dysfunction of the electron transport chain [84]. The mitochondrial enzyme p66shc seems to play an important role in regulation of oxidative stress induction, since mice lacking p66hc present with reduced ROS production, improved endothelial function and increased lifespan [85]. However, conflicting findings exist on the effects of antioxidants on vascular function in elderly humans. For example, a study on vitamin $\mathrm{E}$ reported that its administration does not reduce endothelial dysfunction in older adults [86]. In contrast, a more recent clinical trial demonstrated acute reversal of endothelial dysfunction in elderly patients after oral administration of an antioxidant cocktail [87].

\section{Conclusions}

The NO pathway and endothelial dysfunction are part of the principal mechanisms involved in the vascular aging process. A better understanding of the complex interactions between them represents an important target for future research. Therapeutic strategies designed to improve endothelial function or provide an alternative source of NO should be primary aims in the drive to reduce the incidence of cardiovascular disease in the elderly. Moreover, studies need to better investigate the effects of antioxidant therapy on endothelial dysfunction in aging.

\section{Abbreviations}

FRTA: Free-radical theory of aging; IGF1: Insulin-like growth factor 1; FOXO3A: Forkhead box O3; Hsp: Heat shock protein; eNOS: Nitric oxide synthase; ROS: Reactive oxygen species; ISS: IGF1-insulin signal; AMPK: 5' adenosine monophosphate-activated protein kinase; ApoE: Apolipoprotein E; CAMK: $\mathrm{Ca}^{2+} /$ calmodulin-dependent protein kinase; BH4: Tetrahydrobiopterin; ADMA: Dimethylarginine; Sirt-1: Sirtuin 1; NADPH oxidase: Nicotinamide adenine dinucleotide phosphate-oxidase; MnSOD: Manganese superoxide dismutase.

\section{Competing interests}

The authors declare that they have no competing interests.

\section{Authors' contribution}

$A A P$ and $C V$ wrote the first draft; subsequent drafts were written by AC, AF, $\mathrm{FV}$, who had the overall supervision of the review processing. All authors read and approved the final manuscript.

\section{Author details}

${ }^{1}$ Cardiovascular Research Unit, IRCCS Multimedica, Milan, Italy. ${ }^{2}$ Department of Medicine and Surgery, University of Salerno, Salerno, Italy. ${ }^{3}$ Vascular Physiopathology Unit, IRCCS INM Neuromed, Pozzilli, (IS), Italy. ${ }^{4}$ Instituto di Tecnologie Biomediche-CNR, Segrate, (MI), Italy.

Received: 6 November 2012 Accepted: 13 November 2012 Published: 15 November 2012 


\section{References}

1. Rubner M: Das Problem der Lebensdauer und seine Beziehungen zum Wachstum und Ernahrung. Munich, Germany: Oldenburg; 1908.

2. Pearl R: The Rate of Living, Being an Account of Some Experimental Studies on the Biology of Life Duration. New York: Alfred A. Knopf; 1928

3. Harman D: Aging: a theory based on free radical and radiation chemistry. J Gerontol 1956, 11:298-300.

4. Harman D: The aging process. Proc Natl Acad Sci U S A 1981, 78:7124-7128.

5. Herrero A, Barja G: ADP-regulation of mitochondrial free radical production is different with complex I- or complex II-linked substrates: implications for the exercise paradox and brain hypermetabolism. J Bioenerg Biomembr 1997, 29:241-249.

6. Hulbert AJ: On the importance of fatty acid composition of membranes for aging. J Theor Biol 2005, 234:277-288.

7. Perls T, Wilmoth J, Levenson R, Drinkwater M, Cohen M, Bogan H, Joyce $E$, Brewster S, Kunkel L, Puca A: Life-long sustained mortality advantage of siblings of centenarians. Proc Natl Acad Sci U S A 2002, 99:8442-8447.

8. Terry DF, Sebastiani P, Andersen SL, Perls TT: Disentangling the roles of disability and morbidity in survival to exceptional old age. Arch Intern Med 2008, 168:277-283.

9. Puca AA, Andrew P, Novelli V, Anselmi CV, Somalvico F, Cirillo NA, Chatgilialoglu C, Ferreri C: Fatty acid profile of erythrocyte membranes as possible biomarker of longevity. Rejuvenation Res 2008, 11:63-72.

10. Shmookler Reis RJ, Xu L, Lee H, Chae M, Thaden JJ, Bharill P, Tazearslan C, Siegel E, Alla R, Zimniak P, Ayyadevara S: Modulation of lipid biosynthesis contributes to stress resistance and longevity of $C$. elegans mutants. Aging (Albany NY) 2011, 3:125-147.

11. Kato T, Shimano H, Yamamoto T, Ishikawa M, Kumadaki S, Matsuzaka T, Nakagawa Y, Yahagi N, Nakakuki M, Hasty AH, et al: Palmitate impairs and eicosapentaenoate restores insulin secretion through regulation of SREBP-1c in pancreatic islets. Diabetes 2008, 57:2382-2392.

12. Chatterjee MT, Khalawan SA, Curran BP: Cellular lipid composition influences stress activation of the yeast general stress response element (STRE). Microbiology 2000, 146(Pt 4):877-884

13. Terry DF, McCormick M, Andersen S, Pennington J, Schoenhofen E, Palaima E, Bausero M, Ogawa K, Perls TT, Asea A: Cardiovascular disease delay in centenarian offspring: role of heat shock proteins. Ann N Y Acad Sci 2004, 1019:502-505.

14. Kermorvant-Duchemin E, Sennlaub F, Sirinyan M, Brault S, Andelfinger G, Kooli A, Germain S, Ong H, D'Orleans-Juste P, Gobeil F Jr, et al: Transarachidonic acids generated during nitrative stress induce a thrombospondin-1-dependent microvascular degeneration. Nat Med 2005, 11:1339-1345.

15. Nisoli E, Tonello C, Cardile A, Cozzi V, Bracale R, Tedesco L, Falcone S, Valerio A, Cantoni O, Clementi $\mathrm{E}$, et al: Calorie restriction promotes mitochondrial biogenesis by inducing the expression of eNOS. Science 2005, 310:314-317.

16. Puca AA, Chatgilialoglu C, Ferreri C: Lipid metabolism and diet: possible mechanisms of slow aging. Int J Biochem Cell Biol 2008, 40:324-333.

17. Mattson MP: Hormesis defined. Ageing Res Rev 2008, 7:1-7.

18. Yang $W$, Hekimi S: A mitochondrial superoxide signal triggers increased longevity in Caenorhabditis elegans. PLOS Biol 2010, 8:e1000556.

19. Ristow M, Schmeisser S: Extending life span by increasing oxidative stress. Free Radic Biol Med 2011, 51:327-336.

20. Weindruch R, Walford RL, Fligiel S, Guthrie D: The retardation of aging in mice by dietary restriction: longevity, cancer, immunity and lifetime energy intake. J Nutr 1986, 116:641-654.

21. Guevara-Aguirre J, Balasubramanian P, Guevara-Aguirre M, Wei M, Madia F, Cheng CW, Hwang D, Martin-Montalvo A, Saavedra J, Ingles S, et al: Growth hormone receptor deficiency is associated with a major reduction in pro-aging signaling, cancer, and diabetes in humans. Sci Transl Med 2011, 3:70ra13.

22. Bluher M, Kahn BB, Kahn CR: Extended longevity in mice lacking the insulin receptor in adipose tissue. Science 2003, 299:572-574.

23. Ogg S, Paradis S, Gottlieb S, Patterson Gl, Lee L, Tissenbaum HA, Ruvkun G: The Fork head transcription factor DAF-16 transduces insulin-like metabolic and longevity signals in C. elegans. Nature 1997, 389:994-999.

24. Cau SB, Carneiro FS, Tostes RC: Differential modulation of nitric oxide synthases in aging: therapeutic opportunities. Front Physio/ 2012, 3:218

25. Caruso C, Passarino G, Puca A, Scapagnini G: "Positive biology": the centenarian lesson. Immun Ageing 2012, 9:5.
26. Ferrario A, Villa F, Malovini A, Araniti F, Puca AA: The application of genetics approaches to the study of exceptional longevity in humans: potential and limitations. Immun Ageing 2012, 9:7

27. Shen L, Wang DQ, Tso P, Jandacek RJ, Woods SC, Liu M: Apolipoprotein E reduces food intake via $\mathrm{PI} 3 \mathrm{~K} / \mathrm{Akt}$ signaling pathway in the hypothalamus. Physiol Behav 2011, 105:124-128.

28. Anselmi CV, Malovini A, Roncarati R, Novelli V, Villa F, Condorelli G, Bellazzi $\mathrm{R}$, Puca AA: Association of the FOXO3A locus with extreme longevity in a southern Italian centenarian study. Rejuvenation Res 2009, 12:95-104.

29. Flachsbart F, Caliebe A, Kleindorp R, Blanche $H$, von Eller-Eberstein $H$, Nikolaus S, Schreiber S, Nebel A: Association of FOXO3A variation with human longevity confirmed in German centenarians. Proc Natl Acad Sci U S A 2009, 106:2700-2705.

30. Willcox BJ, Donlon TA, He Q, Chen R, Grove JS, Yano K, Masaki KH, Willcox DC, Rodriguez B, Curb JD: FOXO3A genotype is strongly associated with human longevity. Proc Natl Acad Sci U S A 2008, 105:13987-13992.

31. Wojtaszewski JF, Nielsen P, Hansen BF, Richter EA, Kiens B: Isoform-specific and exercise intensity-dependent activation of 5'-AMP-activated protein kinase in human skeletal muscle. J Physio/ 2000, 528(Pt 1):221-226.

32. Lewis GD, Farrell L, Wood MJ, Martinovic M, Arany Z, Rowe GC, Souza A, Cheng S, McCabe EL, Yang E, et al: Metabolic signatures of exercise in human plasma. Sci Transl Med 2010, 2:33-37.

33. Racioppi L, Means AR: Calcium/calmodulin-dependent kinase IV in immune and inflammatory responses: novel routes for an ancient traveller. Trends Immunol 2008, 29:600-607.

34. Malovini A, Illario M, laccarino G, Villa F, Ferrario A, Roncarati R, Anselmi CV Novelli V, Cipolletta E, Leggiero E, et al: Association study on long-living individuals from Southern Italy identifies rs10491334 in the CAMKIV gene that regulates survival proteins. Rejuvenation Res 2011, 14:283-291.

35. Palacios OM, Carmona JJ, Michan S, Chen KY, Manabe Y, Ward JL 3rd, Goodyear LJ, Tong Q: Diet and exercise signals regulate SIRT3 and activate AMPK and PGC-1alpha in skeletal muscle. Aging (Albany NY) 2009, 1:771-783

36. Nisoli E, Clementi E, Paolucci C, Cozzi V, Tonello C, Sciorati C, Bracale R, Valerio A, Francolini M, Moncada S, Carruba MO: Mitochondrial biogenesis in mammals: the role of endogenous nitric oxide. Science 2003, 299:896-899.

37. Zhou E, Qing D, Li J: Age-associated endothelial dysfunction in rat mesenteric arteries: roles of calcium-activated $\mathrm{K}(+)$ channels $(\mathrm{K}(\mathrm{ca})$ ). Physiol Res/Academia Scientiarum Bohemoslovaca 2010, 59:499-508.

38. Durik M, Kavousi M, van der Pluijm I, Isaacs A, Cheng C, Verdonk K, Loot AE, Oeseburg H, Bhaggoe UM, Leijten F, et al: Nucleotide excision DNA repair is associated with age-related vascular dysfunction. Circulation 2012, 126:468-478.

39. Donato AJ, Gano LB, Eskurza I, Silver AE, Gates PE, Jablonski K, Seals DR: Vascular endothelial dysfunction with aging: endothelin-1 and endothelial nitric oxide synthase. Am J Physiol Heart Circ Physiol 2009, 297:H425-432.

40. Lahteenvuo J, Rosenzweig A: Effects of aging on angiogenesis. Circ Res 2012, 110:1252-1264.

41. El Assar M, Angulo J, Vallejo S, Peiro C, Sanchez-Ferrer CF, Rodriguez-Manas $L$ : Mechanisms involved in the aging-induced vascular dysfunction. Front Physiol 2012, 3:132

42. Seals DR, Jablonski KL, Donato AJ: Aging and vascular endothelial function in humans. Clin Sci (Lond) 2011, 120:357-375.

43. Feletou M, Kohler R, Vanhoutte PM: Nitric oxide: Orchestrator of endothelium-dependent responses. Ann Med 2011, 44:694-716.

44. Garaliene V: [Endothelium and nitric oxide]. Medicina (Kaunas) 2008, 44:564-569.

45. Loscalzo J: Nitric oxide insufficiency, platelet activation, and arterial thrombosis. Circ Res 2001, 88:756-762.

46. Hossain M, Qadri SM, Liu L: Inhibition of nitric oxide synthesis enhances leukocyte rolling and adhesion in human microvasculature. J Inflamm (Lond) 2012, 9:28.

47. Cirino G, Fiorucci S, Sessa WC: Endothelial nitric oxide synthase: the Cinderella of inflammation? Trends Pharmacol Sci 2003, 24:91-95.

48. Aicher A, Heeschen C, Mildner-Rihm C, Urbich C, Ihling C, Technau-Ihling K, Zeiher AM, Dimmeler S: Essential role of endothelial nitric oxide synthase for mobilization of stem and progenitor cells. Nat Med 2003, 9:1370-1376.

49. Li W, Mital S, Ojaimi C, Csiszar A, Kaley G, Hintze TH: Premature death and age-related cardiac dysfunction in male eNOS-knockout mice. J Mol Cell Cardiol 2004, 37:671-680. 
50. Vecchione C, Carnevale D, Di Pardo A, Gentile MT, Damato A, Cocozza G, Antenucci G, Mascio G, Bettarini U, Landolfi A, et al: Pressure-induced vascular oxidative stress is mediated through activation of integrinlinked kinase 1/betaPIX/Rac-1 pathway. Hypertension 2009, 54:1028-1034

51. Vecchione C, Patrucco E, Marino G, Barberis L, Poulet R, Aretini A, Maffei A, Gentile MT, Storto M, Azzolino O, et al: Protection from angiotensin IImediated vasculotoxic and hypertensive response in mice lacking PI3Kgamma. J Exp Med 2005, 201:1217-1228.

52. Walsh T, Donnelly T, Lyons D: Impaired endothelial nitric oxide bioavailability: a common link between aging, hypertension, and atherogenesis? J Am Geriatr Soc 2009, 57:140-145.

53. Chou TC, Yen MH, Li CY, Ding YA: Alterations of nitric oxide synthase expression with aging and hypertension in rats. Hypertension 1998, 31:643-648

54. Tsikas D, Haufe S, Stichtenoth DO, Jordan J: Nitric oxide and hypertension. J Hypertens 2012, 30:625-626. author reply 626-627.

55. Tiritilli A: [Nitric oxide (NO), vascular protection factor. NO: role in aging]. Presse Med 1998, 27:1071-1072.

56. Hirai DM, Copp SW, Hageman KS, Poole DC, Musch TI: Aging alters the contribution of nitric oxide to regional muscle hemodynamic control at rest and during exercise in rats. J App/ Physio/ 2011, 111:989-998.

57. Maurya PK, Rizvi SI: Alterations in plasma nitric oxide during aging in humans. Indian J Biochem Biophys 2009, 46:130-132.

58. Raju SV, Barouch LA, Hare JM: Nitric oxide and oxidative stress in cardiovascular aging. Science of aging knowledge environment: SAGE KE 2005, 2005:re4.

59. Forstermann U: Nitric oxide and oxidative stress in vascular disease. Pflugers Archiv: European journal of physiology 2010, 459:923-939.

60. Dzurik R, Spustova V, Gajdos M: Nitric oxide modulation of metabolic and haemodynamic balance. Bratis/ Lek List 2005, 106:252-256.

61. Chauhan A, More RS, Mullins PA, Taylor G, Petch C, Schofield PM: Agingassociated endothelial dysfunction in humans is reversed by L-arginine. J Am Coll Cardiol 1996, 28:1796-1804.

62. Vasquez-Vivar J, Kalyanaraman B, Martasek P, Hogg N, Masters BS, Karoui H, Tordo P, Pritchard KA Jr: Superoxide generation by endothelial nitric oxide synthase: the influence of cofactors. Proc Natl Acad Sci U S A 1998, 95:9220-9225

63. Schulze F, Maas R, Freese R, Schwedhelm E, Silberhorn E, Boger RH: Determination of a reference value for $N(G), N(G)$-dimethyl-L-arginine in 500 subjects. Eur J Clin Invest 2005, 35:622-626.

64. Berkowitz DE, White R, Li D, Minhas KM, Cernetich A, Kim S, Burke S, Shoukas AA, Nyhan D, Champion HC, Hare JM: Arginase reciprocally regulates nitric oxide synthase activity and contributes to endothelial dysfunction in aging blood vessels. Circulation 2003, 108:2000-2006.

65. Cooke JP: ADMA: its role in vascular disease. Vasc Med 2005, 10(Suppl 1):S11-17.

66. Rippe C, Lesniewski L, Connell M, LaRocca T, Donato A, Seals D: Short-term calorie restriction reverses vascular endothelial dysfunction in old mice by increasing nitric oxide and reducing oxidative stress. Aging Cell 2010, 9:304-312.

67. Cernadas MR, Sanchez de Miguel L, Garcia-Duran M, Gonzalez-Fernandez F, Millas I, Monton M, Rodrigo J, Rico L, Fernandez P, de Frutos T, et al: Expression of constitutive and inducible nitric oxide synthases in the vascular wall of young and aging rats. Circ Res 1998, 83:279-286.

68. Ota H, Akishita M, Eto M, lijima K, Kaneki M, Ouchi Y: Sirt1 modulates premature senescence-like phenotype in human endothelial cells. J Mol Cell Cardiol 2007, 43:571-579.

69. Mattagajasingh I, Kim CS, Naqvi A, Yamamori T, Hoffman TA, Jung SB, DeRicco J, Kasuno K, Irani K: SIRT1 promotes endothelium-dependent vascular relaxation by activating endothelial nitric oxide synthase. Proc Natl Acad Sci U S A 2007, 104:14855-14860.

70. Donato AJ, Magerko KA, Lawson BR, Durrant JR, Lesniewski LA, Seals DR: SIRT-1 and vascular endothelial dysfunction with ageing in mice and humans. J Physio/ 2011, 589:4545-4554.

71. Ota H, Eto M, Ogawa S, lijima K, Akishita M, Ouchi Y: SIRT1/eNOS axis as a potential target against vascular senescence, dysfunction and atherosclerosis. J Atheroscler Thromb 2010, 17:431-435.

72. Higashi Y, Sasaki S, Nakagawa K, Kimura M, Noma K, Hara K, Jitsuiki D, Goto C, Oshima T, Chayama K, Yoshizumi M: Tetrahydrobiopterin improves aging-related impairment of endothelium-dependent vasodilation through increase in nitric oxide production. Atherosclerosis 2006 186:390-395.

73. Donato AJ, Eskurza I, Silver AE, Levy AS, Pierce GL, Gates PE, Seals DR: Direct evidence of endothelial oxidative stress with aging in humans: relation to impaired endothelium-dependent dilation and upregulation of nuclear factor-kappaB. Circ Res 2007, 100:1659-1666.

74. Vecchione C, Aretini A, Marino G, Bettarini U, Poulet R, Maffei A, Sbroggio M, Pastore L, Gentile MT, Notte A, et al: Selective Rac-1 inhibition protects from diabetes-induced vascular injury. Circ Res 2006, 98:218-225.

75. Vecchione C, Gentile MT, Aretini A, Marino G, Poulet R, Maffei A, Passarelli F, Landolfi A, Vasta A, Lembo G: A novel mechanism of action for statins against diabetes-induced oxidative stress. Diabetologia 2007, 50:874-880

76. Durrant JR, Seals DR, Connell ML, Russell MJ, Lawson BR, Folian BJ, Donato AJ, Lesniewski LA: Voluntary wheel running restores endothelial function in conduit arteries of old mice: direct evidence for reduced oxidative stress, increased superoxide dismutase activity and down-regulation of NADPH oxidase. J Physiol 2009, 587:3271-3285.

77. Donato AJ, Lesniewski LA, Delp MD: Ageing and exercise training alter adrenergic vasomotor responses of rat skeletal muscle arterioles. J Physiol 2007, 579:115-125.

78. Ungvari Z, Orosz Z, Labinskyy N, Rivera A, Xiangmin Z, Smith K, Csiszar A Increased mitochondrial $\mathrm{H} 2 \mathrm{O} 2$ production promotes endothelial NFkappaB activation in aged rat arteries. Am J Physiol Heart Circ Physiol 2007, 293:H37-47.

79. Yang YM, Huang A, Kaley G, Sun D: eNOS uncoupling and endothelial dysfunction in aged vessels. Am J Physiol Heart Circ Physiol 2009, 297:H1829-1836.

80. Rodriguez-Manas L, El-Assar M, Vallejo S, Lopez-Doriga P, Solis J, Petidier R, Montes M, Nevado J, Castro M, Gomez-Guerrero C, et al: Endothelial dysfunction in aged humans is related with oxidative stress and vascular inflammation. Aging Cell 2009, 8:226-238.

81. Pang CY, Ma YS, Wei YU: MtDNA mutations, functional decline and turnover of mitochondria in aging. Front Biosci 2008, 13:3661-3675.

82. van der Loo B, Labugger R, Skepper JN, Bachschmid M, Kilo J, Powell JM, Palacios-Callender M, Erusalimsky JD, Quaschning T, Malinski T, et al: Enhanced peroxynitrite formation is associated with vascular aging. J Exp Med 2000, 192:1731-1744.

83. Csiszar A, Labinskyy N, Jimenez R, Pinto JT, Ballabh P, Losonczy G, Pearson $\mathrm{KJ}$, de Cabo R, Ungvari Z: Anti-oxidative and anti-inflammatory vasoprotective effects of caloric restriction in aging: role of circulating factors and SIRT1. Mech Ageing Dev 2009, 130:518-527.

84. Ungvari Z, Labinskyy N, Gupte S, Chander PN, Edwards JG, Csiszar A: Dysregulation of mitochondrial biogenesis in vascular endothelial and smooth muscle cells of aged rats. Am J Physiol Heart Circ Physiol 2008, 294:H2121-2128.

85. Camici GG, Cosentino F, Tanner FC, Luscher TF: The role of p66Shc deletion in age-associated arterial dysfunction and disease states. J Appl Physiol 2008, 105:1628-1631.

86. Simons LA, von Konigsmark M, Simons J, Stocker R, Celermajer DS: Vitamin E ingestion does not improve arterial endothelial dysfunction in older adults. Atherosclerosis 1999, 143:193-199.

87. Wray DW, Nishiyama SK, Harris RA, Zhao J, McDaniel J, Fjeldstad AS, Witman MA, Ives SJ, Barrett-O'Keefe Z, Richardson RS: Acute reversal of endothelial dysfunction in the elderly after antioxidant consumption. Hypertension 2012, 59:818-824.

doi:10.1186/1742-4933-9-26

Cite this article as: Puca et al:: Endothelial nitric oxide synthase, vascular integrity and human exceptional longevity. Immunity \& Ageing 2012 9:26. 